\title{
Divergent Trajectories of BMI over Age for Adult Baka Pygmy People and their Sympatric Non-Pygmy Populations
}

\author{
Stephan M. Funk ${ }^{1,2} \cdot$ Belén Palomo Guerra $^{3}$ • Natalia de Mena Martínez ${ }^{4} \cdot$ Amy Ickowitz $^{6}$ • Julia E. Fa ${ }^{5,6}$
}

Published online: 12 May 2020

(C) The Author(s) 2020

\begin{abstract}
Differences in socioeconomic conditions and health have been reported for African Pygmies and their sympatric populations of other ethnic groups. We collected anthropometric data in southern Cameroon from Baka and their Bantu neighbours, and also extracted data from the five available and representative Demographic and Health Surveys (DHS) in sub-Saharan African countries that have Pygmy populations. Our results show that the Baka exhibited a weak but significant decline of body mass index (BMI) with age $(p=0.003)$ without a sex difference. At a larger geographical scale, all five DHS surveys revealed flat or negative slopes for Pygmy BMI with age. Except for one non-Pygmy ethnic group, the slope was less than for all DHS- surveyed non-Pygmy African ethnicities. Pygmy populations were the least wealthy in all surveys, but no pattern for anaemia levels versus BMI emerged. We argue that the declining or stagnant trajectory of Pygmy BMI over age is most concerning, since this sets them apart not only from all other ethnic groups in the region, but from the general trend of increasing body weight over age. We suggest that our results do not reflect the influence of ethnicity per se, but the fact Pygmy populations are socially and materially deprived groups. These findings are fully aligned with the extraordinary high premature death rate among the Baka and need to be addressed for sustainable development initiatives to be effectively implemented.
\end{abstract}

Keywords Indigenous Peoples $\cdot$ Body mass index (BMI) $\cdot$ Malnutrition $\cdot$ Baka Pygmies $\cdot$ Bantu $\cdot$ Southern Cameroon $\cdot$ Congo Basin · Africa

\section{Introduction}

Indigenous peoples constitute only about 400 million people worldwide, but represent an incredible diversity of cultures, speaking over 4000 of the roughly 7000 languages in the world (UN Department of Economic and Social Affairs

Julia E. Fa

jfa949@gmail.com

NatureHeritage, Jersey, Channel Islands, UK

2 Centro de Excelencia en Medicina Traslacional, Universidad de La Frontera, Temuco, Chile

3 Hospital Universitario de Móstoles, Móstoles, Calle Río Júcar, s/n, 28935 Móstoles, Madrid, Spain

4 Hospital Universitario Severo Ochoa, Av. de Orellana, s/n, 28911 Leganés, Madrid, Spain

5 Center for International Forestry Research (CIFOR), CIFOR Headquarters, Bogor 16115, Indonesia

6 Department of Natural Sciences, School of Science and the Environment, Manchester Metropolitan University, Manchester M1 $5 \mathrm{GD}, \mathrm{UK}$
2009). However, most Indigenous groups are marginalized and excluded from political and economic power, suffer from systematic discrimination, and are often dispossessed of their ancestral lands and deprived from their way of life (UN Department of Economic and Social Affairs 2009). As a consequence, many Indigenous Peoples are disproportionately poor and suffer from major health issues as a result. Although the magnitude of the disparity in health varies by country and over time, Indigenous Peoples are known to suffer from higher rates of disease and premature death than the sympatric majority populations (Anderson et al. 2016). In a systematic review of indigenous health worldwide, the Baka Pygmies in Cameroon stand out, exhibiting the highest reported disparity in premature death (Anderson et al. 2016). Life expectancy at birth for Baka Pygmies is on average 35 years of age, compared to the sympatric Bantu population who live about 22 years longer (The Lancet 2016).

The denomination "Pygmy" is a synthetic description of a culturally diverse range of hunter-gatherer sub-Saharan peoples found within the tropical moist forests in the Congo Basin (Froment 1993; Hewlett 2014; Olivero et al. 2016). In some countries including Cameroon, Pygmy populations have been 
relocated as a result of displacements by other ethnic groups (Dounias and Froment 2006) or have been forced to relocate and sedentarise (Knight 2006). These changes have had consequences on their lifestyles and nutrition (Reyes-García et al. 2019). Although recent state legislation has recognized the rights of autochthones in all countries where Pygmies are found, they are increasingly marginalised (Ohenjo et al. 2006; Wodon et al. 2012).

Pygmy people have a characteristically low stature (average adult height of $155 \mathrm{~cm}$ ). Pygmy growth patterns are unique, stemming from specific genetic foundations that determine the African Pygmy phenotype (Ramírez Rozzi et al. 2015; Pemberton et al. 2018). Average standing height varies among Pygmy groups, from $142 \mathrm{~cm}$ amongst the Western Congo Basin Efe to $161 \mathrm{~cm}$ in the Eastern Twa (Froment 2014). Morphology and growth dynamics also differ between Western and Eastern groups, likely because of genetic differentiation (Ramírez Rozzi and Sardi 2010; Ramírez Rozzi et al. 2015). The mechanisms linking genetics and nutritional status in Pygmies, such as fat deposition, remain unknown. The body mass index (BMI) has been shown to be only weakly correlated with genetic ancestry, indicating a greater contribution of non-genetic factors to body weight than to height (Pemberton et al. 2018).

BMI, measured as weight $(\mathrm{kg})$ divided by the square of height $\left(\mathrm{m}^{2}\right)$, is a useful standard to assess nutritional status of people and is commonly used in epidemiological studies on weight and risk of death (Flegal et al. 2014). BMI is simply a measure of size and it does not directly evaluate individual health and even performs rather poorly to identify the percentage of body fat (Garn 1986; Nuttall 2015). Nevertheless, it is a useful parameter to assess the risk of developing individual and population heath issues, and has been widely used in determining public health policies (Nuttall 2015). In a review of BMI of Pygmy populations compared to their sympatric non-Pygmy neighbours, Pygmy men and women had consistently lower mean BMI in eight and nine studies, respectively (Froment 2014). Conversely, in a study comparing Pygmies with their counterparts across their entire sympatric distribution area, no statistical difference in mean BMI was found (Pemberton et al. 2018). The authors argued that this might be a result of sampling focused on rural individuals only (Pemberton et al. 2018) rather than a mixture of rural and more urban subjects (Froment 2014). It is also possible that in some situations the socioeconomic and nutritional status of Pygmies may have improved. Moreover, the sample composition of individuals from Pygmy groups versus groupfocussed studies could have influenced the mean BMIs since both stature and genetics differ among Pygmy tribes, as seen between Eastern and Western groups (Pemberton et al. 2018).

Four standard categories described by the World Health Organization can be used to classify individuals according to their BMI: underweight $(<18.5)$, normal weight (18.5-24.9), overweight (25.0-29.9), and obesity ( $\geq 30)$ (Flegal et al. 2014). Underweight can result from the impact of certain diseases, and can also be the cause of disease and mortality. Importantly, maternal prepregnancy underweight BMI is associated with increasing risk-adjusted preterm birth (Girsen et al. 2016), and increased mortality (Visscher et al. 2000; Ringbäck Weitoft et al. 2008). Disease burden due to malnutrition is high and a conservative estimate is that at least $32 \%$ of the global burden would be eliminated by eradicating malnutrition (Mason et al. 2003).

Here, we analyse BMI of Pygmy populations and their non-Pygmy neigbours across their distribution range in Central Africa. We first compare BMI of Baka with nonPygmy, mainly Bantu, people in south-eastern Cameroon where we conducted health campaigns and collected anthropomorphic data. Second, we use the published Demographic and Health Surveys (DHS) data from five sub-Saharan countries. DHS uses standardised and representative sampling and objective information on anthropometric measures, thus allowing comparisons between countries and over time (Corsi et al. 2012; Croft et al. 2018). Since BMI is an estimator for nutritional status and impacts mortality and health, it is a first systematic approach to make sense of the health discrepancy in the Baka, which is the largest observed for Indigenous peoples (Anderson et al. 2016).

\section{Methods}

\section{Study Area}

This study was conducted in Baka villages located along the Djoum-Mintom road south of the Dja Faunal Reserve (Réserve de faune du Dja, also known as Réserve de Biosphère Dja), southeast Cameroon (Fig. 1). Baka villages have around 70 inhabitants, and are found alongside but separate from Bantu villages on the same stretch of road, generally no larger than 400 people. The Bantu-speaking population is made up of different ethnic groups (Bulu, Fang, and Zaman).

All villages are surrounded by relatively intact tropical rainforest vegetation from which villagers obtain wild meat and medicinal and food plants. Before the turn of the 1960s, when the Baka adopted agriculture (Leclerc 2012), their subsistence was based on a combination of hunting, gathering, fishing, "paracultivation" of wild yams, and the acquisition of cultivated products by barter (Bahuchet 1992; Dounias and Froment 2006).

Since their adoption of agriculture and especially as a result of the sedentarization of groups, most Baka groups engage in wage labour and obtain cash from the sale of wild meat or non-timber forest products (NTFPs) in addition to their traditional activities such as hunting and gathering. A number of state and other actors (conservation, logging, mining, and 


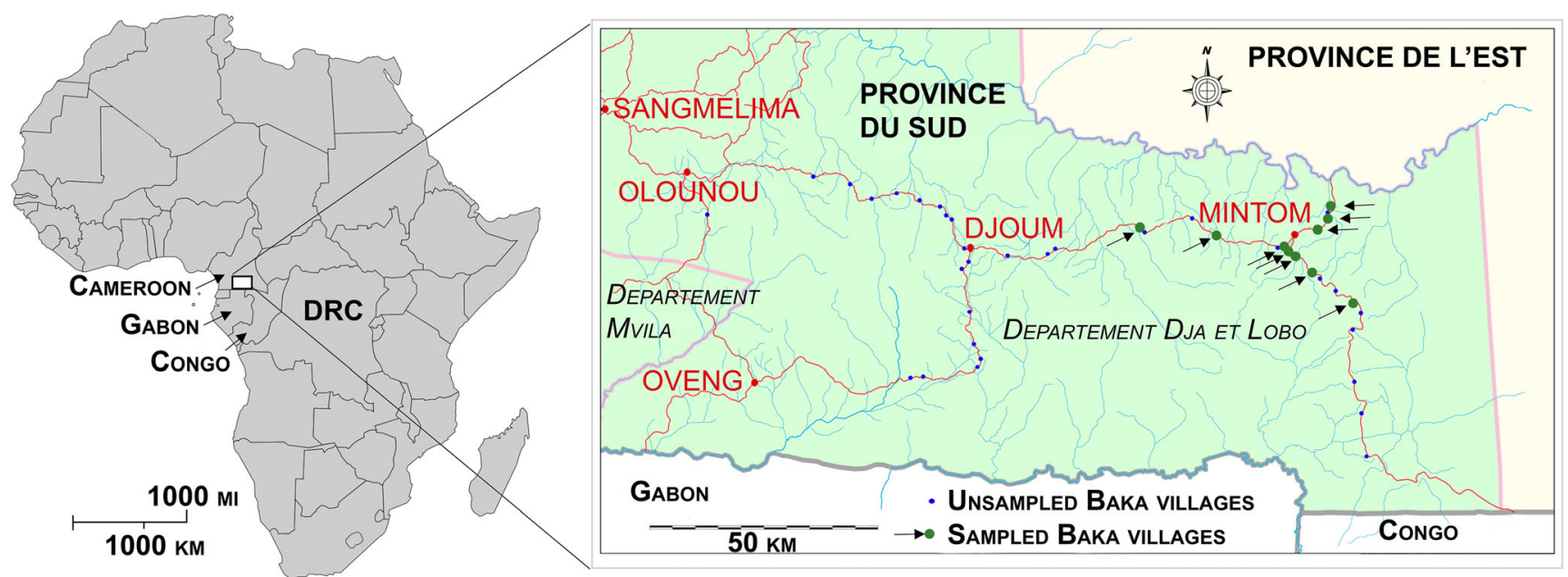

Fig. 1 Map indicating the countries where DHS surveys compared Pygmy and non-Pygmy populations and the location of the sudy site in south-eastern Cameroon

tourism development projects) have affected social services delivery to Baka communities in Cameroon (Pemunta 2019). In some cases, this has led to their eviction and has caused conflict with development agents and even their adjacent Bantu communities.

Food security of most Baka groups, and particularly those settled along roads, is generally poor and wealth levels are extremely low (Dounias 2016). Evidence from other indigenous groups shows that the change from nomadic hunting, gathering, and trapping to sedentary village life has been associated with a marked decline in physical and mental health. Baka people living in isolated villages away from roads and therefore markets retain a more diverse and healthy diet (Reyes-García et al. 2019).

\section{Health Data Collection}

\section{Cameroon}

Health data were collected from adult Baka Pygmies and their sympatric Bantu populations during two health campaigns in 2018 and 2019 in our study area (see above). Data were gathered from 11 out of 42 Baka villages distributed along the Djoum-Mintom road axis of the Dja et Lobo Department in the south of the country bordering Gabon and the Republic of Congo (Fig. 1; Funk et al. submitted). In two prior campaigns in 2010 and 2018, we sampled Baka children in 34 villages, but restricted the 2018 and 2019 campaigns to fewer villages in the northeastern distribution area because of security concerns.

We set up mobile clinics in each village. All inhabitants were encouraged to attend irrespective of their ethnicity and health status. Clinics were run by the Spanish NGO Zerca y Lejos $(\mathrm{ZyL})$, which has been working on health and development issues in the region for over 15 years providing primary education and health facilities and agricultural support (Zerca y Lejos 2018). We followed the Demographic and Health Surveys' criteria (Corsi et al. 2012) by setting the minimum age for an adult at 15 years, but we excluded 15 year olds in the analysis because of data deficiencies for them.

Where necessary, we offered treatment for any ailment diagnosed at the clinics. Our samples covered approximately two thirds of the Baka population in 2018 of the ten study villages for which we could estimate the percentage of attendance from demographic data (Funk et al. submitted)' but Bantu attendance was lower because our work was primarily focussed on Baka villages.

During each clinic, we verbally informed attendees of the purpose of the study and procedures used. Those who agreed to participate and to provide their data gave written informed consent. Prior to data analysis, the names of participants were dissociated from all datasheets to maintain confidentiality. We recorded village, self-declared age and ethnicity (Baka and Bantu), weight $(\mathrm{kg})$, height $(\mathrm{cm})$, and a range of diagnostic and clinical data as described elsewhere (Funk et al. accepted). A day before the clinic, we held meetings with the village chiefs from whom we obtained permission to carry out our work. Our study was undertaken under the auspices of the Arrete No. 00034 of the Minstere de L'Administration Territoriales et de la Decentralisation awarded to ZyL to perform health and development work within the Djoum-Mintom region.

\section{Central Africa}

Alongside our field work, we also extracted height and weight data for Pygmy and sympatric populations from five of the 57 Low and Middle Income Countries surveyed by DHS that are 
inhabited by Pygmy populations (DHS 2019). These five analysable surveys distinguish ethnicities and provided measures on weight and height: Cameroon 2004, Republic of Congo 2005 and 2011, Democratic Republic of Congo (DRC) 2013, and Gabon 2012. No such surveys were available for the other countries where Pygmies live (Froment 1993, 2014; Hewlett 2014). DHS surveys for Angola, Rwanda, and Burundi were included, as ethnicity was not recorded. We also extracted data on the DHS-calculated wealth index and anaemia as estimators of individual living standards and nutrition status. Only data from adult females were available.

\section{Statistical Analyses}

BMI $\left(\mathrm{kg} \mathrm{m}^{-2}\right)$ was calculated and conventional BMI thresholds were applied to characterize underweight $(\leq 18.5)$ and obesity $(\geq 30)$. Differences between the frequency of underweight and obesity between Baka and Bantu were evaluated by Fisher's exact test. In both the field and DHS data sets, pregnant women were removed from the analysis. DHS data were filtered for extreme values for height $(<100 \mathrm{~cm}$ or $>$ $200 \mathrm{~cm})$ and weight $(<25 \mathrm{~kg}$ or $>200 \mathrm{~kg}$ ) to account for data inconsistencies; no such extreme values were observed in the field data set. The non-parametric Mann-Whitney-Wilcoxon Test was used to test wether age and height distributions in Baka and Bantu are identical. For both data sets, linear regression was used with age, sex, and ethnicity as independent variables. For the field data set, statistical analysis was performed using Wald test statistics of Generalized Estimating Equations (GEE), which are a general method for analysing data containing longitudinally collected, possibly autocorrelated observations, as in our case (Liang and Zeger 1986). We tested two models with GEE, with and without ethnicity, and used ANOVA to select the most adequate model. For the DHS data set, a second model added the weath index as an independent variable to ascertain whether observed ethnic differences in BMI were correlated with relative wealth and, thus, living standards between ethnicities. The DHS wealth index summarizes households' ownership of physical assets, housing materials, and access to fresh water and sanitation facilities (DHS Program 2020). As the DHS data set did not include longitudinal observations, statistical analysis was performed using ANOVA models. For both data sets the variance explained by fitting a linear regression model was estimated by multiple $R^{2}$. Differences in levels of obsesity, underweight, and anaemia between Baka and Bantu were statistically tested using the two-sided Fisher's exact test for the field data set. Published literature data on mean BMI in different Pygmy populations were statistically tested for for sex-specific BMI using the sign test together with a two-sided binomial test. We used the statistical software R (R Foundation for Statistical Computing 2016) for all analyses. GEE analysis was conducted by the geeglm function as implemented in the R package "geepack" (Halekoh et al. 2006; Højsgaard et al. 2019).

\section{Results}

During our four health campaigns, anthropometric data were collected in 11 of 46 villages (Fig. 1). A total of 402 persons (331 Baka and 71 Bantu) aged between 16 and 70 years were samples, of which 44 persons were measured more than once. Pregnant women $(n=28)$ were excluded from the BMI analysis (see Table 1 for an overview of sex ratios, age structure and summary statistics of weight, height, and BMI). The dominant age class in Baka was the 21 - 30 year class and in Bantu the 41-50 year class. The three-year age difference between Baka and Bantu was not significant (Mann-Whitney U test, $n=402, \mathrm{~W}=10,216, p=0.07)$ but reflected the lower life expectancy of Baka recorded in the literature (The Lancet 2016). Baka were on average $13.2 \mathrm{~cm}$ smaller than Bantu (MannWhitney $\mathrm{U}$ test, $\mathrm{n}=402, \mathrm{~W}=3685, p<0.0001$ ).

Baka exhibited a strong decline in BMI with increasing age without obvious gender-specific differences (Fig. 2a). GEE

Table 1 Summary of sample sizes and population characteristics of Baka Pygmies and Bantu people in south-eastern Cameroon

\begin{tabular}{|c|c|c|c|c|}
\hline & \multicolumn{2}{|l|}{ Baka } & \multicolumn{2}{|c|}{ Bantu } \\
\hline & $\mathrm{m}$ & $\mathrm{f}$ & $\mathrm{m}$ & $\mathrm{f}$ \\
\hline $\mathrm{N}$ (sampled) & 141 & 214 & 35 & 40 \\
\hline N (pregnant, excluded) & - & 24 & - & 4 \\
\hline $\mathrm{N}$ (analysed) & 331 & & 71 & \\
\hline repeated measures & 21 & 22 & 0 & 1 \\
\hline \multicolumn{5}{|l|}{ Age classes } \\
\hline $16-20$ & \multicolumn{2}{|l|}{71} & \multicolumn{2}{|l|}{14} \\
\hline $21-30$ & \multicolumn{2}{|l|}{99} & \multicolumn{2}{|l|}{15} \\
\hline $31-40$ & \multicolumn{2}{|l|}{77} & \multicolumn{2}{|l|}{10} \\
\hline $41-50$ & \multicolumn{2}{|l|}{44} & \multicolumn{2}{|l|}{20} \\
\hline $51-60$ & \multicolumn{2}{|l|}{26} & \multicolumn{2}{|l|}{10} \\
\hline $61-70$ & \multicolumn{2}{|l|}{14} & \multicolumn{2}{|l|}{2} \\
\hline mean $\pm \mathrm{SD}$ age & \multicolumn{2}{|l|}{$32.9 \pm 13.1$} & \multicolumn{2}{|c|}{$36 \pm 14$} \\
\hline \multicolumn{5}{|l|}{ Difference Baka - Bantu } \\
\hline height $\pm \mathrm{SD}(\mathrm{m})$ & \multicolumn{2}{|l|}{$1.5 \pm 0.0794$} & \multicolumn{2}{|c|}{$1.64 \pm 0.0911$} \\
\hline \multicolumn{5}{|l|}{ Difference Baka - Bantu } \\
\hline weight $\pm \mathrm{SD}(\mathrm{kg})$ & \multicolumn{2}{|l|}{$46.2 \pm 7.7$} & \multicolumn{2}{|c|}{$61.4 \pm 10.7$} \\
\hline \multicolumn{5}{|l|}{ Difference Baka - Bantu } \\
\hline underweight (\%) & \multicolumn{2}{|l|}{23.6} & \multicolumn{2}{|c|}{5.63} \\
\hline obese $(\%)$ & \multicolumn{2}{|l|}{0.604} & \multicolumn{2}{|c|}{7.04} \\
\hline $\mathrm{BMI} \pm \mathrm{SD}$ & \multicolumn{2}{|l|}{$20.3 \pm 2.77$} & \multicolumn{2}{|c|}{$22.8 \pm 3.58$} \\
\hline Difference Baka - Bantu & & & & \\
\hline
\end{tabular}


Fig. 2 BMI of Baka men and women in relation to age (a) and mean BMIs of the present study and published data (b); violet and black: Baka Pygmies and different Pygmy groups from published and unpublished studies summarized by Froment (2014), green: across Pygmy group means from Pemberton et al. (2018); red: present field data; orange: means of the DHS data)
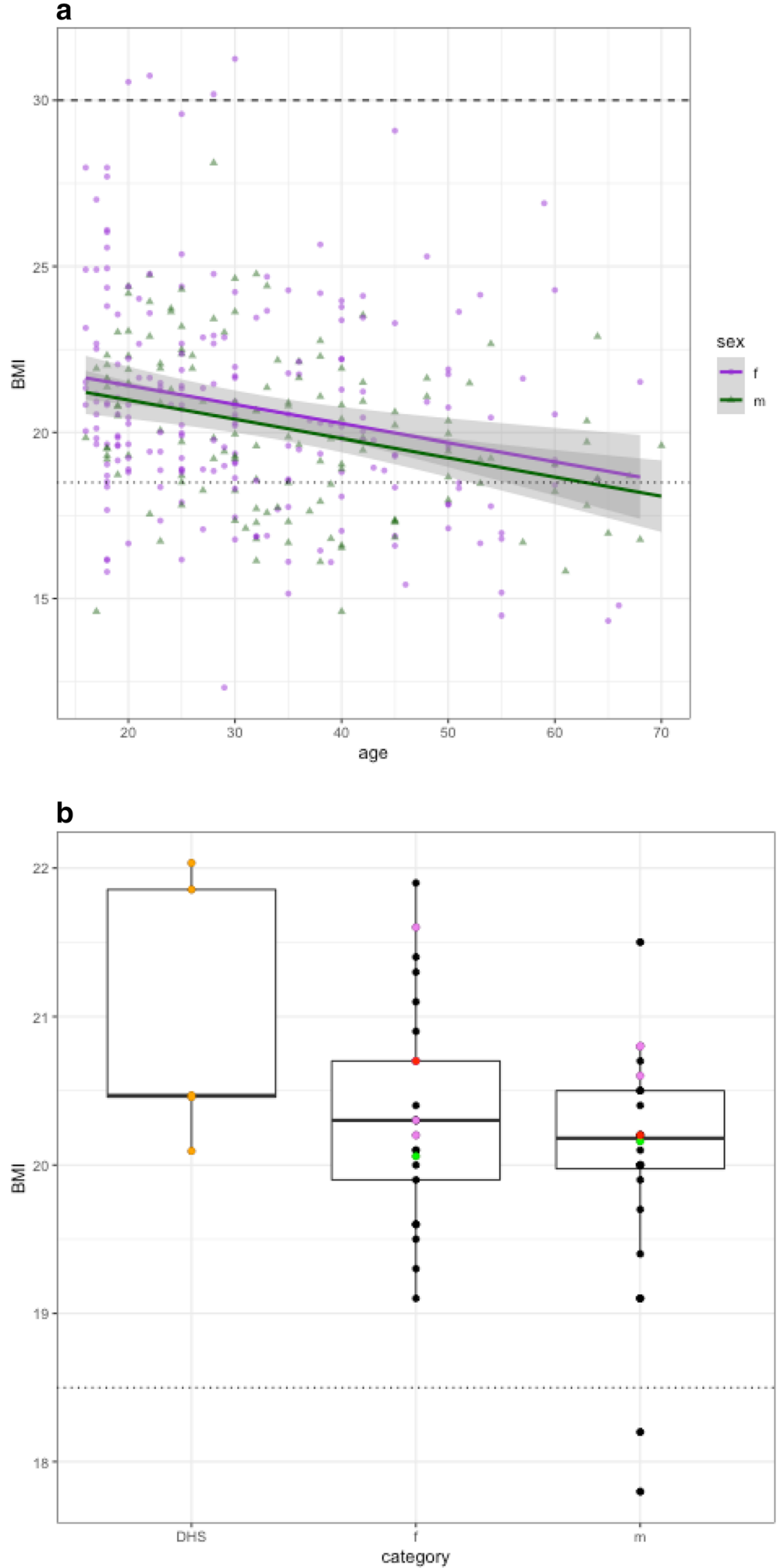
analysis confirmed significant age-specificity (Wald statistics: 19.3, $p<0.0001$ ) but no gender-specificity (Wald statistics: $0.7, p=0.4)$. Overall, the variance in BMI was large and the linear regression model explained only $6 \%$ of it (multiple $\left.\mathrm{R}^{2}=0.0573\right)$. For both sexes' pooled mean BMI $( \pm \mathrm{SD})$ was $20.3 \pm 2.77$. Mean BMI for males and females was within the range reported for 28 Western and Eastern Pygmy populations from the 1930s onwards reported by Froment (Froment 2014) (Fig. 2b), and for a survey across populations (Pemberton et al. 2018). The 18 of these studies that provided mean BMI for males and for females did not indicate a sexspecific difference in BMI $(p=0.63)$. Bantu showed a BMI distribution independent of age $(p=0.21)$ but with a strong sex bias $(p=0.0009)$ explaining $16.5 \%$ of the observed variance.

Mean \pm SD BMI was with $22.8 \pm 3.58$ on average 2.45 points higher for Bantu than Baka (Fig. 3). The GEE model for the pooled Baka/Bantu data was significant for age (Wald statistics: $6.57, p=0.01$ ) but not for sex (Wald statistics: 3.8, $p=0.051$ ) when ethnicity was not considered. However, age (Wald statistics: $11.4, p=0.007$ ), sex (Wald statistics: 5.6, $p=$ 0.018 ), and ethnicity (Wald statistics: $35.5, p<0.0001$ ) was significant in the full model. The ANOVA for the GEE models showed that the model with ethnicity is significant over the model without ethnicity $\left(\mathrm{DF}=1,{ }^{2} \mathrm{Chi}^{2}=35.5, \mathrm{p}<0.0001\right)$. The linear regression model explained $12.5 \%$ of the observed variance (multiple $\mathrm{R}^{2}=0.125$ ). Significantly more Baka than
Bantu were underweight $(23.6 \%$ and $5.6 \%$, respectively, $p=$ $0.0006)$ but significantly less often obese $(0.6 \%$ and $7.0 \%$, respectively, $p=0.005$ ).

All DHS surveys revealed no or negative growth of BMI of Pygmies with increasing age (Fig. 4a). With only one exception, the non-Pygmy Bakukuya people in Congo 2005, the slope of the growth for Pygmy populations was less than all non-Pygmy African ethnicities in Cameroon in $2004(n=47$ non-Pygmy ethnicities), Congo 2005 and 2011 ( $n=90$ and $n=10$, respectively), DRC in $2013(n=8)$, and Gabon in $2012(n=7)$ (see Fig. 5 for the linear regression of Pygmy people compared to the largest ethnic sample for the five DHS surveys). A convergent pattern clearly separated Pygmy and non-Pygmy people. In all cases, the values for the regression lines of non-Pygmy people were higher with a positive slope over age than for Pygmy people, whose slopes were always negative notwithstanding their larger confidence intervals, which reflect generally smaller sample sizes for Pygmy versus non-Pygmy people. ANOVA showed significance of ethnicity as an independent variable with the exception for DRC in 2013 (Table 2). Pygmy people were also the least wealthy populations in all surveys (Fig. 4b). When including the wealth index in the ANOVA, wealth was always significant (Table 2). ANOVA of all DHS surveys combined with BMI as dependent variable was significant for all independent variables: age $(\mathrm{F}=524.5, p<0.001)$, Pygmy $(\mathrm{F}=$ $50.9, \mathrm{p}<0.001)$, wealthindex $(\mathrm{F}=723.1, \mathrm{p}<0.001)$, and
Fig. 3 BMI of Baka and Bantu in relation to age with age, sex and ethnicity as independent variables

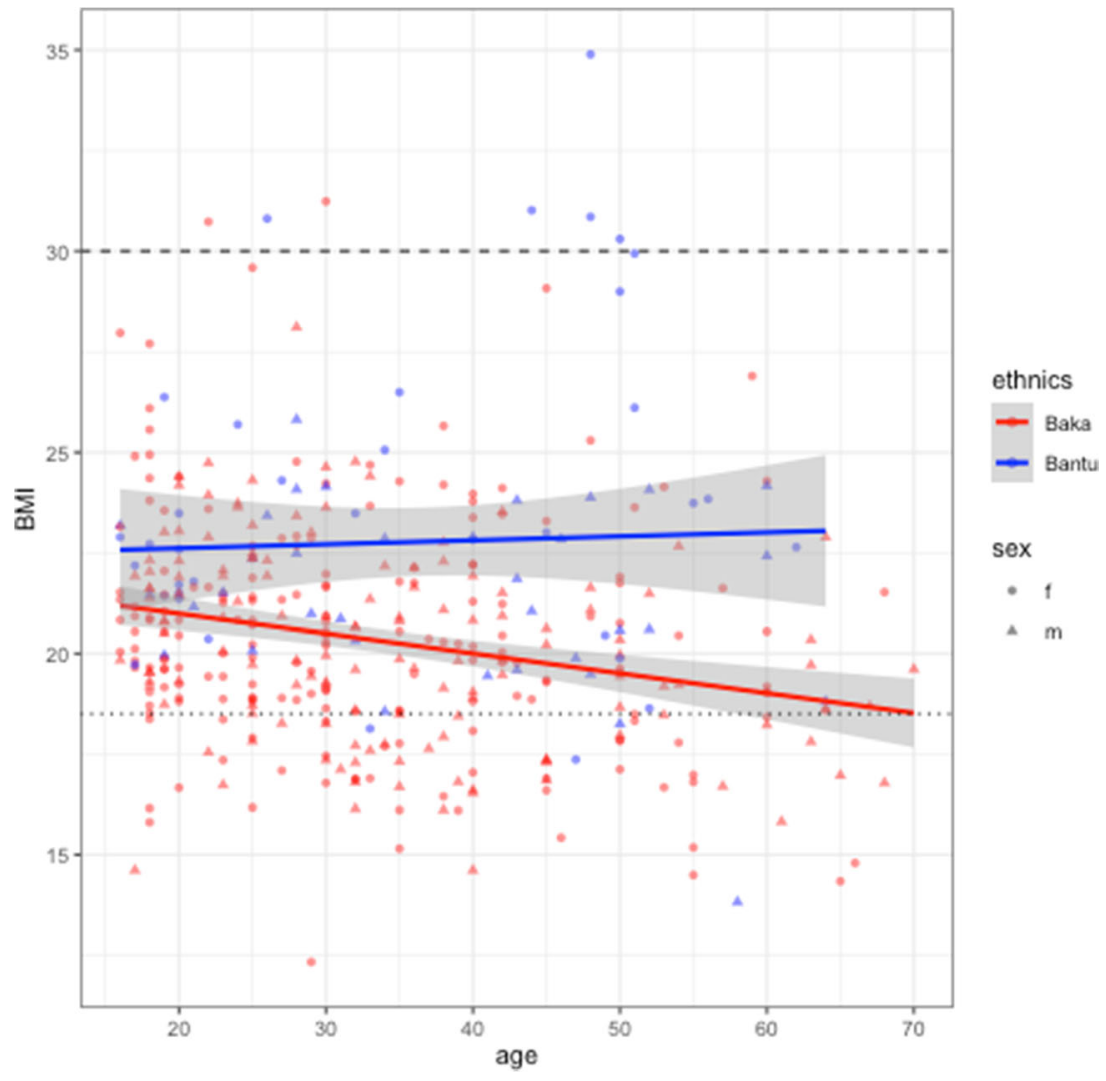




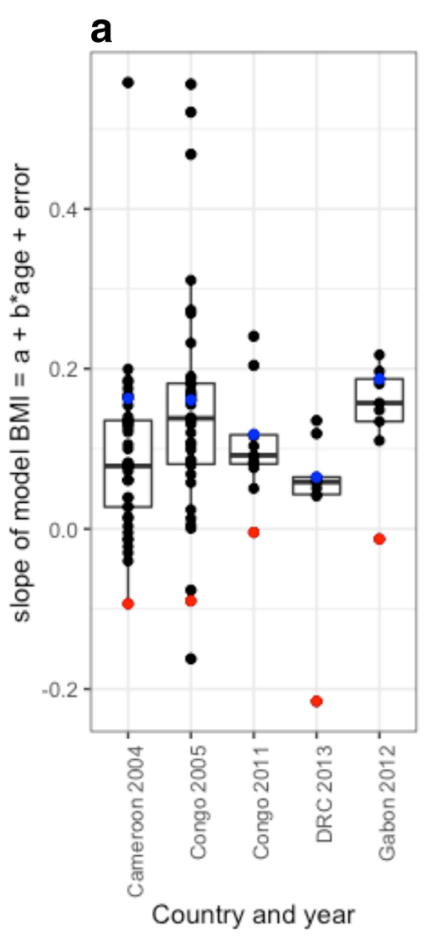

Fig. 4 Comparison of Pygmies and non-Pygmies from five DHS surveys across the Pygmy distribution where ethnicity was recorded. Shown are the slopes of the multiple regression model $\mathrm{BMI}=\mathrm{a}+\mathrm{b}$ *age + error $(\mathbf{a})$,
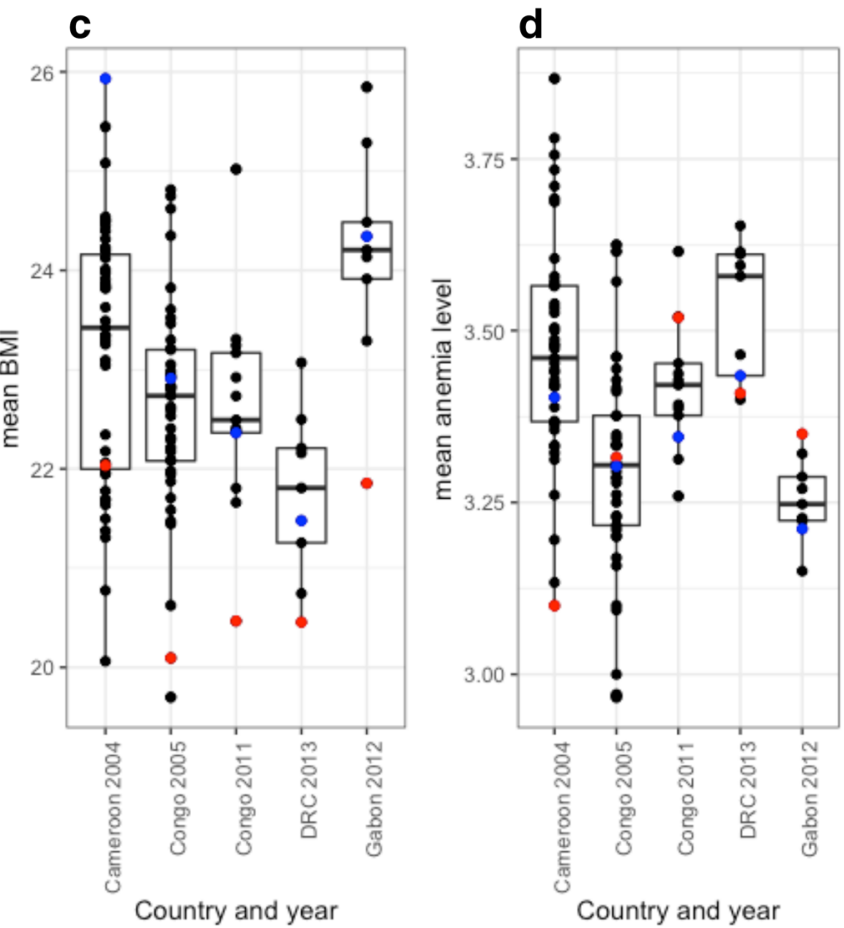

red: Pygmy, black: non-Pygmy, blue: largest non-Pygmy sample

the mean wealth index (b), mean BMI (c) and the mean anaemia level (d). Red dots represent Pygmy sample and blue dots the non-Pygmy ethnicity with the largest sample size
Fig. 5 Comparison of BMI of Pygmy individuals and individuals of non-Pygmy ethnicity with the largest sample size, from five DHS surveys across the Pygmy distribution where ethnicity was recorded

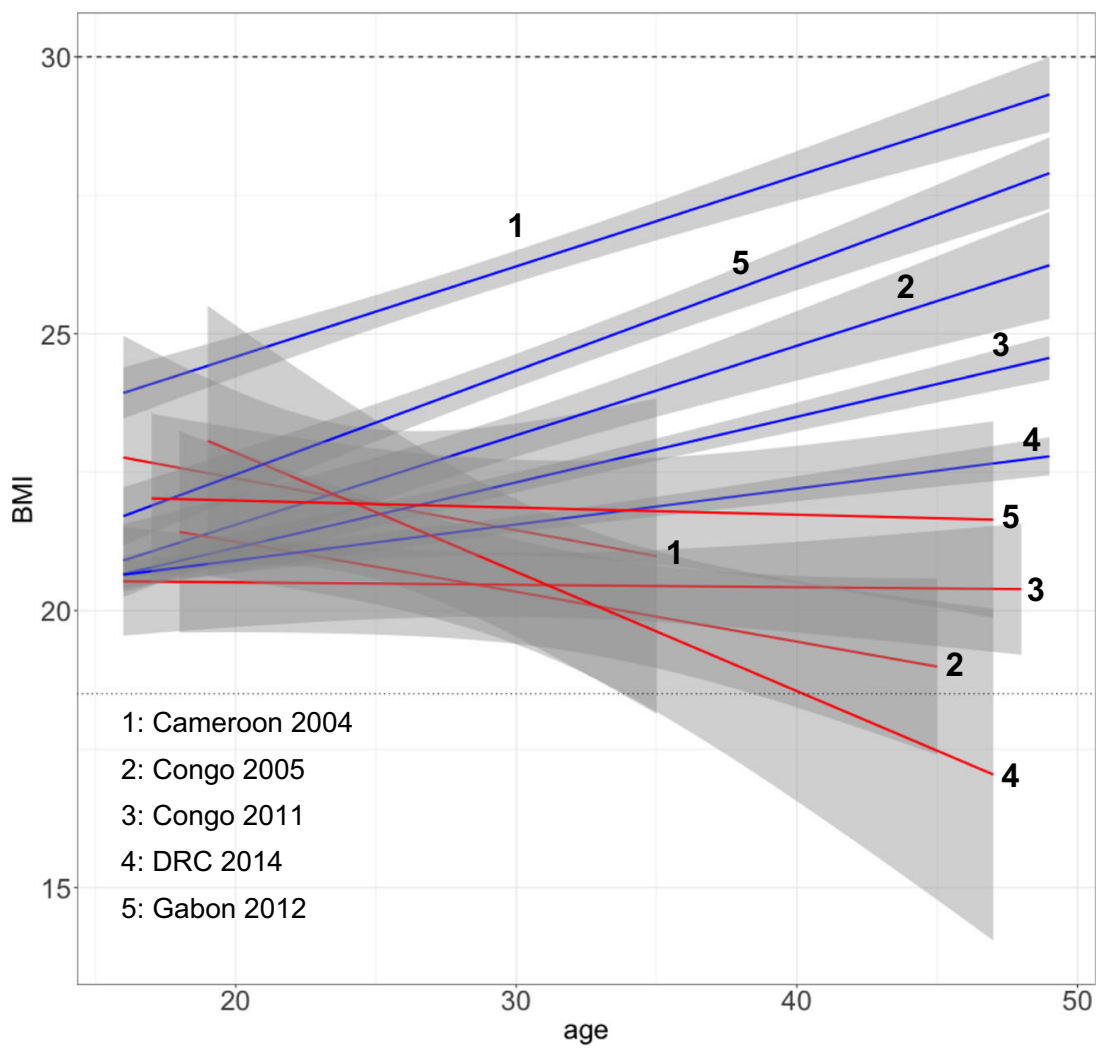


DHS survey $(\mathrm{F}=220.5, \mathrm{p}<0.001)$, with the latter parameter indicating country-specificity of the surveys.

Mean BMI showed the same pattern as for the slopes of Congo 2005 and 2011, DRC 2013, and Gabon 2012 (Fig. 4c). However, the mean for Cameroon 2004 of $22.03 \pm 1.81$ was not amongst the smallest of the surveyed non-Pygmy populations (Table 2), which is consistent with the fact that only the Cameroon 2014 survey did not include Baka aged over 35 years, thus excluding smaller BMI values for older people that can be expected due to the significantly negative slope of BMI with increasing age (Fig. 5). The mean for Cameroon 2004 is the largest reported mean BMI for any surveyed Pygmy population (Fig. 1b), thus highlighting that mean BMI values are misleading when the negative slope is not considered. The mean BMI for Gabon 2012 is almost as high as the highest recorded BMI in Pygmies (Fig. 2b). It is still the smallest mean BMI for any Gabonese population, which exhibited the highest joint means for all DHS surveys (Fig. 4c). Anaemia levels did not show any pattern separating Pygmy populations from non-Pygmies.

\section{Discussion}

The comparison of unbiased estimation of BMI values for different populations requires representative sampling (Corsi et al. 2012; Croft et al. 2018). In general, the Pygmy populations in the DHS surveys have very small sample sizes, approximately $1 \%$ to $4 \%$ of the largest sample of any nonPygmy population in any of the five DHS surveys (Fig. 4). This reflects the Absolute sample sizes, which are also small, ranging from $n=10$ (Cameroon 2004) to $n=90$ (Congo 2011). Although the DHS surveys are carefully designed to be representative, undetected sampling bias might impact the statistical results. Thus, whilst results for any single DHS survey might have undetected bias, the joint results of the five DHS surveys together with the Baka/Bantu survey are robust as they all show the same trends.

BMI either declined with age or remained stagnant in all Pygmy populations. The methodological implication is that mean BMI values are age-dependent and, thus, dependent on the age-structure of the population sample. Age dependence in western populations, where BMI increases with age, has been well documented, leading to the use of ageadjusted weight standards for health monitoring and the insurance industry (Andres 1985). Consequently, reported mean population BMI values (Froment 2014; Pemberton et al. 2018) can not be directly compared with each other. By modelling age in multivariate regression analysis, we confirm the previous observation that Pygmy populations indeed have lower BMI than their neigbours in the field study and in four of five DHS surveys. The one notable exception of Cameroon in 2014 is a result of the Pygmy sample being composed of 
only younger people. The slope of BMI over age is negative, making it likely that Pygmies' mean BMI would also be at the lower end of all sampled ethnicities if a more representative age structure had been included in that DHS survey.

The BMI clearly has limitations as an indicator of body mass, but its use remains widespread because it is an easily obtained metric (Nuttall 2015). It is important to note that the index needs to be interpreted alongside other parameters for individual and population health. For Baka Pygmies, two aspects are important to consider alongside the observation that Baka BMI is on average lower that that of their non-Pygmy neighbours. First, the DHS data demonstrate a corraletion between BMI and household wealth and correspond with Bakas' generally low socioeconomic status (Anderson et al. 2016; The Lancet 2016). Second, the declining or stagnant BMI trajectory over age is of particular concern, which sets the Pygmy populations apart not only from all other ethnic entities in the region but from the general trend of increasing body weight and, thus, BMI, over age (Andres 1985). The observed negative trend in the field study and in three out of five DHS studies increases health risks associated with underweight and is, consequently, fully aligned with the extraordinary high premature death rate among Baka, who die on average 22 years earlier than their non-Pygmy neigbours (Anderson et al. 2016).

Whilst Pygmy people have not generally experienced the negative impact of diet change observed elsewhere, such as increased rates of overweight, obesity, or diabetes (Popkin 2004), the sedentarisation of Pygmy populations clearly has not mitigated malnutrition. In the field and DHS data sets Pygmy populations had lower obesity percentages and higher underweight percentage than their neighbours. There is evidence from other Pygmy groups that the loss of customary lands to logging, development, and conservation has caused impoverishment and nutritional deficiency, particularly if they lack alternative lands on which to grow their own food (Jackson 2006). The gazettement of the Mgahinga, Bwindi, and Echuya forests in Uganda as protected areas in 1991 left Batwa Pygmies as squatters on the lands of neighbouring farmer communities (Jackson 2005). The Batwas' loss of their lands and resource base has made it very difficult for them to secure basic survival needs, resulting in severe poverty and hardship. When Batwa families were given land, under-five mortality rates dropped from $59 \%$ to $18 \%$, demonstrating the crucial importance of land for survival.

The shift to a sedentary way of life is known to affect food availability and distribution and particularly influences children and pregnant women's nutritional status and health (Dounias and Froment 2006). As traditionally egalitarian social systems are eroded, the responsibility for children's well being and household food provisioning has fallen increasingly in groups such as the Twa to women, who have to rely on begging or badly-paid wage labour to obtain food have great difficulty meeting their families' needs (Jackson 2006). Hewlett (1987) found that Aka Pygmy nutrition is considerably better in the forest because hunting for protein-rich game meat occurs regularly, while in the village camp Aka depend largely upon the starchy village diet of manioc and plantains. Sedentary Kola and Baka Pygmies also tend towards an excess intake of energydense foods that are rich in fat and free sugars but low in complex carbohydrates. Evidence from epidemiological studies has confirmed a link between such a diet and risks of degenerative chronic diseases of middle and later adult life, particularly cardiovascular diseases and certain types of cancer. Other nutritional disorders such as anaemia, obesity, hypertension, elevated cholesterol levels, and diabetes are also appearing among these former hunter-gatherers. The BMI indexes of sedentary huntergatherers are significantly lower than those of their farming neighbours (Dounias and Froment 2006).

Hagino et al. (2014) carried out research with the Baka in southeastern Cameroon in order to assess whether their nutritional status had changed after social transition. Settlement policy and agriculture development for the Baka have been promoted in the Republic of Cameroon for decades. The Baka community have also been affected by logging companies and the influx of a large-scale cash economy. Despite the presence of social stress as a result of changing circumstances in the village, indices concerning the physical development of the children, adult body size, and body composition all implied that the nutritional status of the Baka residents was generally good. Hagino et al. (2014) argue that supplementing their time spent in the village with time in forest camps reduced stress and helped them to maintain their nutritional status.

In a recent study, Lewnard et al. (2014) suggest that food insecurity may be associated with an increased risk of malaria. Among Batwa in Kanungu, Uganda, it was found that individuals who are particularly undernourished or severely foodinsecure may have elevated risk for $P$. falciparum parasitemia. Lewnard et al. suggest that this finding may motivate integrated control of malaria and malnutrition in low-transmission settings.

The comparison of the BMI dynamics over age and the underweight percentages highlight the peril Pygmy groups find themselves in. The stepwise multivariate analysis demonstrates that the key is not ethnicity per se, but the biased wealth amongst ethnicities, with the Pygmies being the most deprived group. Consequently, Pygmies represent a general trend that "the poor stay thinner" (Neuman et al. 2011) as shown by DHS surveys across 52 Low and Middle Income Countries (Neuman et al. 2011; Subramanian et al. 2011). If the Millennium Development Goals are to be fulfilled, this major wealth discrepancy must be adressed urgently in order to successfully tackle the health discrepancy. It is not sufficient to make Pygmies give up their hunter-gatherer lifestyle and to provide them with opportunities for subsistence farming, but subsistence farming must address the nutritional requirements for a healthy diet. 
Acknowledgments For assistance in the field we thank Mirabelle Assampelle, N Afoumpam Poni, G Ros Brull, M Abossolo E Ávila Martín, R Okale, B Ango Ze, A Moreno Carrión, R Sánchez Expósito, Hissein Amazia and Julienne Meyina from the Zerca y Lejos NGO, Madrid, Spain, Mohamadou Aminou Abdou, Y Hadam Sibama, and R Penda from the Faculté de Médecine et Sciences Biomédicales, Université de Yaoundé, Yaoundé, Cameroon, C García Sebastián from the Hospital Universitario Ramón y Cajal, Madrid, C Ruiz de Loizaga García from the Hospital Universitario Príncipe de Asturias, Madrid, F López-Romero Salazar from the Hospital Universitario 12 de Octubre, Madrid, and I. Álvarez Reyes from the Consorci Sanitari Integral de L'Hospitalet de Llobregat, Barcelona, Spain. JEF was partly funded by the US Agency for International Development as part of the Bushmeat Research Initiative of the CGIAR research program on Forests, Tress and Agroforestry. AI acknowledges support from the United States Agency for International Development's Forestry and Biodiversity Office (USAID-FAB) and the CGIAR's research program on Forests, Trees and Agroforestry (FTA).

Funding Information This research was funded by the UK Government's Darwin Initiative (Project No. 24029).

\section{Compliance with Ethical Standards}

Conflict of Interest The authors declare they have no competing interests.

Open Access This article is licensed under a Creative Commons Attribution 4.0 International License, which permits use, sharing, adaptation, distribution and reproduction in any medium or format, as long as you give appropriate credit to the original author(s) and the source, provide a link to the Creative Commons licence, and indicate if changes were made. The images or other third party material in this article are included in the article's Creative Commons licence, unless indicated otherwise in a credit line to the material. If material is not included in the article's Creative Commons licence and your intended use is not permitted by statutory regulation or exceeds the permitted use, you will need to obtain permission directly from the copyright holder. To view a copy of this licence, visit http://creativecommons.org/licenses/by/4.0/.

\section{References}

Anderson I, Robson B, Connolly M, et al (2016) Indigenous and tribal peoples' health (The Lancet-Lowitja Institute Global Collaboration): a population study. The Lancet 388:131-157. https://doi.org/10.1016/S0140-6736(16)00345-7

Andres R (1985) Impact of Age on Weight Goals. Annals of Internal Medicine 103:1030. https://doi.org/10.7326/0003-4819-103-6-1030

Bahuchet, S. (1992). Dans la Forêt D'Afrique Centrale: Les Pygmées Aka Et Baka. PEETERS-SELAF

Corsi DJ, Neuman M, Finlay JE, Subramanian S (2012) Demographic and health surveys: a profile. International Journal of Epidemiology 41:1602-1613. https://doi.org/10.1093/ije/dys 184

Croft TN, Marshall AMJ, Allen CK (2018) Guide to DHS StatisticsDHS-7- The Demographic and Health Surveys Program. ICF, Rockville.

DHS. (2019). The DHS Program - Demographic and Health Surveys. Data. https://dhsprogram.com/data/

DHS Program. (2020). Wealth Index Construction. https://www. dhsprogram.com/topics/wealth-index/Wealth-Index-Construction. cfm. Accessed 5 Mar 2020
Dounias E (2016) From Subsistence to Commercial Hunting: Technical Shift in Cynegetic Practices Among Southern Cameroon Forest Dwellers During the 20th Century. Ecology and Society 21: https://doi.org/10.5751/ES-07946-210123

Dounias E, Froment A (2006) When forest-based hunter-gatherers become sedentary: consequences for diet and health. Unasylva 57:8

Flegal KM, Kit BK, Graubard BI (2014) Body Mass Index Categories in Observational Studies of Weight and Risk of Death. American Journal of Epidemiology 180:288-296. https://doi.org/10.1093/aje/ kwu111

Froment A (1993) Adaptation biologique et variation dans l'espèce humaine : le cas des Pygmées d'Afrique. Bulletins et Mémoires de la Société d'anthropologie de Paris 5:417-448. https://doi.org/10. 3406/bmsap.1993.2371

Froment A (2014) Human biology and the health of African rainforest inhabitants. In: Hunter-gatherers of the Congo basin. Transaction Publishers, New Brunswick, pp 117-164

Funk, S. M., Guerra, B. P., Ickowitz, A. et al. (submitted). WHO child growth standards for Pygmy populations: one size fits all? Human Ecology submitted:

Garn M (1986) Three limitations of the body mass index. American Journal of Clinical Nutrition 44:996-997

Girsen A, Mayo J, Carmichael S, et al (2016) Women's prepregnancy underweight as a risk factor for preterm birth: a retrospective study. BJOG: Int J Obstet Gy 123:2001-2007. https://doi.org/10.1111/ 1471-0528.14027

Hagino, I., Sato, H., Yamauchi, T. (2014). The demographic characteristics and nutritional status for a hunter-gatherer society with social transitions in southeastern Cameroon. African study monographs Supplementary issue: $45-57$

Halekoh, U., Højsgaard, S., Yan, J. (2006) The $R$ Package geepack for Generalized Estimating Equations. Journal of Statistical Software 15:. https://doi.org/10.18637/jss.v015.i02

Hewlett, B. S. (1987). Patterns of paternal holding among Aka pygmies. The father's role: Cross-cultural perspectives 295-330

Hewlett BS (ed) (2014) Hunter-gatherers of the Congo Basin: cultures, histories and biology of African Pygmies. Transaction Publishers, New Brunswick

Højsgaard, S., Halekoh, U., Yan, J., Ekstrøm, C. (2019). Package 'geepack.' Version 1.3-1

Jackson, D. (2005). Implementation of international commitments on traditional forest-related knowledge; indigenous peoples' experiences in Central Africa. In: Newing H (ed) Our knowledge for our survival. Volume I. International Alliance of the Indigenous and Tribal Peoples of the Tropical Forests. Forest Peoples Programme and Centre for International Forestry Research, pp 150-303

Jackson, D. (2006). The Health Situation of Women and Children in Central African Pygmy Peoples. In: Forest Peoples Programme. http://www.forestpeoples.org/es/node/942. Accessed 5 Mar 2020

Knight, J. (2006). Indigenous forest peoples of Gabon face uncertain future. Indigenous affairs 8

Leclerc, C. (2012). L'adoption de l'agriculture chez les Pygmées baka du Cameroun. Editions Quae

Lewnard JA, Berrang-Ford L, Lwasa S, et al (2014) Relative Undernourishment and Food Insecurity Associations with Plasmodium falciparum Among Batwa Pygmies in Uganda: Evidence from a Cross-Sectional Survey. The American Journal of Tropical Medicine and Hygiene 91:39-49. https://doi.org/10.4269/ ajtmh.13-0422

Liang K-Y, Zeger SL (1986) Longitudinal data analysis using generalized linear models. Biometrika 73:13-22

Mason, J. B., Musgrove, P., Habicht, J.-P. (2003). At least one-third of poor countries disease burden is due to malnutrition. Popline

Neuman M, Finlay JE, Davey Smith G, Subramanian S (2011) The poor stay thinner: stable socioeconomic gradients in BMI among women in lower- and middle-income countries. The American Journal of 
Clinical Nutrition 94:1348-1357. https://doi.org/10.3945/ajcn.111. 018127

Nuttall FQ (2015) Body Mass Index: Obesity, BMI, and Health. Nutrition Today 50:117-128. https://doi.org/10.1097/NT.0000000000000092

Ohenjo N, Willis R, Jackson D, et al (2006) Health of Indigenous people in Africa. The Lancet 367:1937-1946. https://doi.org/10.1016/ S0140-6736(06)68849-1

Olivero J, Fa JE, Farfán MA, et al (2016) Distribution and Numbers of Pygmies in Central African Forests. PLoS One 11:e0144499. https:// doi.org/10.1371/journal.pone.0144499

Pemberton TJ, Verdu P, Becker NS, et al (2018) A genome scan for genes underlying adult body size differences between Central African hunter-gatherers and farmers. Human Genetics 137:487-509. https://doi.org/10.1007/s00439-018-1902-3

Pemunta NV (2019) Factors Impeding Social Service Delivery among the Baka Pygmies of Cameroon. Journal of Progressive Human Services 30:211-238. https://doi.org/10.1080/10428232.2019. 1581041

Popkin BM (2004) The Nutrition Transition: An Overview of World Patterns of Change. Nutrition Reviews 62:S140-S143. https://doi. org/10.1111/j.1753-4887.2004.tb00084.x

R Foundation for Statistical Computing. (2016). R. Version 3.3.1 GUI 1.68 Mavericks buildURL https://www.r-project.org

Ramírez Rozzi FV, Sardi ML (2010) Diversity among African Pygmies. PLoS One 5:e13620

Ramírez Rozzi, F. V., Koudou, Y., Froment, A. et al. (2015). Growth pattern from birth to adulthood in African pygmies of known age. Nature Communications 6:. https://doi.org/10.1038/ncomms8672

Reyes-García V, Powell B, Díaz-Reviriego I, et al (2019) Dietary transitions among three contemporary hunter-gatherers across the tropics.
Food Security 11:109-122. https://doi.org/10.1007/s12571-0180882-4

Ringbäck Weitoft G, Eliasson M, Rosén M (2008) Underweight, overweight and obesity as risk factors for mortality and hospitalization. Scandinavian Journal of Public Health 36:169-176. https://doi.org/ $10.1177 / 1403494807085080$

Subramanian S, Perkins JM, Özaltin E, Davey Smith G (2011) Weight of nations: a socioeconomic analysis of women in low- to middleincome countries. The American Journal of Clinical Nutrition 93: 413-421. https://doi.org/10.3945/ajen.110.004820

The Lancet. (2016). Indigenous health: a worldwide focus. The Lancet 388:104. https://doi.org/10.1016/S0140-6736(16)31020-0

UN Department of Economic and Social Affairs. (ed) (2009). State of the World's Indigenous Peoples. United Nations, New York

Visscher TLS, Seidell JC, Menotti A, et al (2000) Underweight and Overweight in Relation to Mortality Among Men Aged 40-59 and 50-69 Years: The Seven Countries Study. American Journal of Epidemiology 151:660-666. https://doi.org/10.1093/ oxfordjournals.aje.a010260

Wodon Q, Backiny-Yetna P, Ben-Achour A (2012) Central Africa: The case of the Pygmies. In: Hall GH, Patrinos HA (eds) Indigenous Peoples, Poverty, and Development. Cambridge University Press, Cambridge, pp 118-148

Zerca y Lejos. (2018). http://zercaylejos.org. Accessed 25 Oct 2018

Publisher's Note Springer Nature remains neutral with regard to jurisdictional claims in published maps and institutional affiliations. 